\title{
Las fuentes del primer libro de empresas políticas en España ${ }^{1}$
}

\author{
Nieves Pena Sueiro \\ Universidade da Coruña \\ npena@udc.es
}

Recepción: 22/11/2013, Aceptación: 09/04/2015, Publicación: 22/12/2015

\begin{abstract}
Resumen
Las Empresas de los Reyes de Castilla de Francisco Gómez de la Reguera es el primer libro de empresas políticas que se conoce en España. En este trabajo nos propusimos estudiar las fuentes iconográficas y textuales de esta obra, porque consideramos que nos permitirían averiguar no solo la erudición del autor, sino también la difusión en España de obras de literatura emblemática europeas.
\end{abstract}

1. Este trabajo se inscribe en el proyecto de investigación Biblioteca Digital Siglo de Oro IV, código FFI2012-34362 financiado por el Ministerio de Economía y Competitividad del Gobierno de España (desde el 01-02-2013 hasta el 31-12-2015). Una de las líneas de investigación de este proyecto es la Literatura Emblemática Hispánica; los resultados de investigación en esta línea pueden consultarse en la Biblioteca virtual de Emblemática <www.bidiso.es/Emblematica>, desde la que el interesado puede acceder de forma libre a varios recursos y colecciones sobre el tema: una base de datos para el estudio de los libros de emblemas espańoles; una base de datos de libros de emblemas traducidos al español; y una bibliografía temática, actualizada constantemente. Tras el establecimiento del corpus de literatura emblemática hispánica y su almacenamiento en la base de datos, el equipo se propone realizar la edición crítica y estudio de estas obras. Hasta el momento se han editado dos: las Empresas políticas de Saavedra Fajardo y las Empresas de los Reyes de Castilla de Gómez de la Reguera; está muy avanzada la edición de los Emblemas morales de Sebastián de Covarrubias y están en preparación cuatro más: las ediciones de las obras de Andrés Mendo, Juan de Horozco, Juan de Borja y Hernando de Soto. La edición y estudio de las principales obras de emblemática supondrá contar con un corpus accesible que permita acercar al lector actual los textos, así como aportar al investigador datos fundamentales sobre algunos aspectos aún poco estudiados (fuentes, influencias, circulación de obras europeas, etc.) de este género que gozó de gran aceptación en el Siglo de Oro. 
El autor, siguiendo el método humanista, sembró de citas y referencias el texto. Del estudio de estas referencias se deduce que Gómez de la Reguera se sirvió de materiales muy variados para el diseño y confección del libro de empresas: los libros de divisas europeos, historias metálicas, monedas y medallas, fueron las principales fuentes de inspiración para la imagen de las empresas; las obras de autores clásicos latinos como Tácito, Cicerón, Séneca, o Plinio el Joven, se emplearon para las glosas. Pero lo que resulta más revelador es desvelar las fuentes implícitas, que el autor no descubre por razones diversas, pero que están presentes en la obra: nos encontramos entonces con autores como Justo Lipsio y Typotius. También podemos constatar, curiosamente, la coincidencia de Gómez de la Reguera y Saavedra Fajardo en la utilización de varias citas, que reproducen incluso con los mismos errores.

\title{
Palabras clave
}

Empresas de los Reyes de Castilla; Gómez de la Reguera; empresas políticas; autores clásicos; fuentes; máximas para príncipes

\begin{abstract}
The Sources of the Spanish First Book of Political Devices

The Empresas de los Reyes de Castilla, by Francisco Gómez de la Reguera, is the earliest known Spanish book of political devices published in Spain. This essay examines the work's iconographical and textual sources, demonstrating not only the author's erudition, but also his role in the spread of European emblem works in Spain.

Like other humanists, its author fills his text with quotations and references. These show him making use of very varied materials: European books of devices and histories of medals and coins being his main sources of inspiration, along with Classical writers, such as Tacitus, Cicero, Seneca and Pliny the Younger. More revealing still is his use of sources that, for various reasons, he does not identify, such as Lipsius and Typotius. Curiously, Gómez de la Reguera also cites a number of sources that he shares with Saavedra Fajardo, with both authors coinciding even in reproducing the same errors.
\end{abstract}

\section{Keywords}

Empresas de los Reyes de Castilla; Gómez de la Reguera; political badges; classical authors; sources; advices for princes 
El estudio de la erudición de un autor del Siglo de Oro se basa, en gran medida, en las fuentes que utilizó para la composición de sus obras. En el caso de las obras de literatura emblemática en general y de los libros de empresas políticas en particular, el estudio de las fuentes resulta, si cabe, de mayor utilidad porque ayuda a vislumbrar el desarrollo del género en España y el conocimiento que tenían los eruditos del siglo Xvi de las obras europeas sobre el tema.

Como es sabido, los libros de emblemas ilustrados formaron parte de la vida intelectual europea de los siglos XVI y XVII. En España, aunque la creación de libros de emblemas hispánicos se hizo esperar hasta finales del siglo $\mathrm{XVI}^{2}$, hubo gran interés por la literatura emblemática; prueba de ello es que las obras editadas por los emblematistas europeos (Alciato, Giovio, Ruscelli, Valeriano, etc.) se difundieron aquí ${ }^{3}$, tanto en sus lenguas originarias como a través de traducciones ${ }^{4}$. Así, en 1558 se publicó en Venecia la traducción al romance por Alonso de Ulloa del Diálogo de las empresas militares y amorosas de Paulo Giovio, que había salido a luz en Roma solo tres años antes 5 . Resulta de interés advertir que en esa edición veneciana se añadieron tres empresas de caballeros españoles acompañadas con un breve comentario, pero sin ilustraciones; son las de Hernán Cortés, Alonso de Ulloa (padre de Alonso de Ulloa, el traductor) y Jerónimo de Urrea. Y fue precisamente el último de estos caballeros quien en su obra Diálogo de la verdadera honra militar, publicada en Venecia en $1566^{6}$, en su segunda parte ${ }^{7}$, trata una cuestión esencial entre los tratadistas italianos de la época: lo que es empresa, señal y divisa, estableciendo diferencias, tanto por su finalidad como por su composición (de colores y metales).

2. Para el desarrollo del género en España, puede verse la introducción a la edición crítica de las Empresas Politicas de Saavedra Fajardo realizada por S. López Poza (1999).

3. La recuperación de inventarios de bibliotecas españolas del Siglo de Oro y su estudio ha permitido que contemos con datos objetivos sobre la presencia de libros de emblemas en bibliotecas; esta información es relevante pues permite constatar qué libros circulaban y a cuáles podían tener acceso los escritores espańoles (incluso los que no viajaron). Sobre bibliotecas del Siglo de Oro, además de una ya abundante bibliografía, puede consultarse la base de datos Inventarios y bibliotecas del Siglo de Oro, <www.bidiso.es/IBSO >, que almacena, hasta el momento, información de 26 bibliotecas. Así por ejemplo, sabemos que la obra de Alciato estaba presente, por lo menos, en las bibliotecas privadas más importantes del Siglo de Oro: había hasta cuatro ediciones en la biblioteca de Lastanosa, y por lo menos dos en las de Ramírez de Prado y el Conde de Gondomar; del Diálogo de las empresas de P. Giovio había dos ediciones en la biblioteca de Ramírez de Prado, una en la biblioteca del conde de Gondomar y otra en la de Lastanosa, etc.

4. La traducción al español del Emblematum liber de Alciato, obra que inicia el género, fue realizada por Bernardino Daza Pinciano y se publicó en Lyon en 1540. Aunque se inició pronto, la labor de traducción de libros de emblemas no fue especialmente activa, pues apenas llegan a la decena las obras traducidas al español.

5. Téngase en cuenta que la traducción al español de la obra de Alciato se publicó nueve años después de su edición en latín.

6. Posteriormente hubo edición póstuma en Madrid, en casa de Francisco Sánchez, en 1575.

7. J. de Urrea (1575: 113 y 114). 
Es evidente pues, que a mediados del siglo XVI la literatura emblemática, y en particular la modalidad de las empresas ${ }^{8}$ (amorosas, heroicas o políticas), tenía seguidores en España; sin embargo, aunque los caballeros, nobles y reyes usaron empresas desde hacía siglos, hubo que esperar hasta 1581 para que se editase el primer libro sobre el tema: Empresas morales, de Juan de Borja, que vio la luz en Praga. Treinta años más tarde Francisco de Villava dio a luz sus Empresas Espirituales, en Baeza, por Fernando Díaz de Montoya en 1613. Y todavía tardarían unos años más los libros de empresas políticas.

El interés por este género seguía presente en España en la corte de Felipe III y de su hijo, Felipe IV. Así, según podemos saber gracias a los escritos del erudito don Francisco Gómez de la Reguera, fue la lectura del Diálogo de las empresas de Paolo Giovio la que hizo notar al Cardenal Infante, don Fernando de Austria, la escasa presencia de empresas de reyes castellanos ${ }^{9}$ y a descubrir la carencia de libros de empresas en España. Aunque no sabemos con certeza cuando sucedió esto - probablemente en la segunda década del siglo XVII- , fue entonces cuando don Fernando de Austria encomendó a Gómez de la Reguera la ardua tarea de recopilar todas las empresas que usaron sus antepasados:

Obediencia fue en mí, no elección del gusto, emprender este trabajo, siendo el primer motivo hallarme un día con el Serenísimo Señor Infante Cardenal D. Fernando que se trató de la materia de las empresas, por hallarse su Alteza en las manos con unas del Giovio, y viendo tan pocas en él de los Reyes de Castilla, me preguntó su Alteza si las habían usado, a quien satisfice entonces y dije tenía algunas de que habían usado nuestros Reyes, que de diferentes autores, medallas y memorias avía juntado. Su Alteza me mando las recogiese todas y se las diese.

Hasta el momento, poco se ha conseguido averiguar acerca de la figura de don Francisco Gómez de la Reguera y Serna: nació en Valladolid en 1595, y, según parece, estudió en su universidad; fue escritor, poeta, traductor, pintor, dibujante, profesor de matemáticas, etc. Aportó a las letras castellanas por lo menos siete obras, entre las que se encuentran una continuación literaria de las Historias Verdaderas de Luciano de Samósata (cuyos dos libros tradujo al espanól) y el primer libro de empresas políticas escritas en castellano. Este erudito gozó de gran estimación entre sus contemporáneos: Lope de Vega, Faria de Sousa, etc., escribieron elogios sobre él, y si el mismo Cardenal Infante le encargó una ardua tarea, está claro que le consideraba capacitado para realizarl $\mathrm{a}^{10}$. Don

8. Para la definición y caracterización de las empresas, véanse los trabajos de S. López Poza (1999), (2007), (2011).

9. Efectivamente, en la obra de Giovio solo se recogen tres empresas de reyes castellanos: las de Fernando el Católico, Carlos V y Felipe II.

10. Para completar los escasos datos biográficos, son fundamentales los testimonios de sus contemporáneos que le consideraron un hombre provisto de un talento prodigioso: así, Juan Antonio Fernández de la Reguera, secretario del Secreto de la Inquisición, indica que fue licenciado en 
Francisco asumió el encargo y decidió formar un libro que reuniese las empresas de los reyes de Castilla.

Para la preparación del libro, don Francisco se valió de materiales propios, según él mismo indica, pero es evidente que habría de servirse también de otras fuentes para tomar datos, por lo menos de aquellas empresas que usaron los reyes de Castilla de las que dispondría de poca información. Asimismo, resulta indudable que Gómez de la Reguera tendría que inspirarse necesariamente en obras extranjeras, puesto que en España, como se ha señalado, no existía literatura emblemática, si bien es cierto que proliferaban desde finales del siglo XVI tratados sobre el gobierno, la razón de estado, la política, la educación de príncipes, y comienzan a salir a luz libros de empresas morales, espirituales, etc. vinculados, en cierto modo, al tema.

Don Francisco aprovechó el encargo de reunir las empresas de los reyes castellanos y realizó un libro de empresas, al que incorporó unas glosas explicativas con un tinte didáctico, insertando reflexiones políticas y máximas para el buen gobierno (seguramente destinadas al Cardenal Infante, considerado más dotado para el gobierno que su hermano, el rey Felipe IV). El perfil didáctico, que acerca el libro de empresas a los espejos de príncipes, se señala desde el título de la obra, Empresas de los Reyes de Castilla, con máximas y documentos para principes, y se vislumbra también en algunos pasajes

[...] para que llegasen a su alteza con algún adorno, formé estas tarjetas, que ejecuté con la pluma en la vitela con la brevedad y facilidad que en ellas se ve, añadiendo a cada una un soneto que fuese breve explicación de la alma de la empresa. Pero juzgando quedaban aún imperfectas y sin la inteligencia que necesitaban algunas, por haberme apartado en algunos sonetos del verdadero concepto político a otro moral aunque se ajustaba a ellas uno y otro para más adorno, hice esos discursos, procurando ceñirme en ellos a la brevedad y que solo sirviesen de explicación a la pintura y letra de estas hierografías, no para ostentar en ellos el ingenio en algunos lances de erudición, y juntamente pudiesen estas máximas políticas dar alguna luz a la tierna juventud de Su Alteza, sin que le desazonase el gusto lo dilatado de los discursos ${ }^{11}$.

Gómez de la Reguera fue muy consciente de estar realizando el primer libro de empresas políticas en Espańa, y así lo señaló en repetidas ocasiones:

Juzgué sería bien recibido este trabajo por la novedad de la materia, pues hasta entonces no sé que se hubiese escrito en nuestra lengua ni esta forma, siendo el primero que abrió senda para que otros ingenios mejores que el mío prosiguiesen

Artes y Jurisprudencia; Lope de Vega (1610) en su Laurel de Apolo habla de su «divino pincel y docta pluma»; Moreno Porcel (1650) dice que «en don Francisco, ingenio y mano son primorosos y conocidos por sus obras». Para un perfil biográfico más amplio, puede verse la introducción a la edición de las Empresas de los Reyes de Castilla (2011).

11. Empresas de los Reyes de Castilla (2011), prólogo. 
el asumpto con doctísimos discursos y conceptos, como lo han hecho después en las que han salido con tanta elegancia, doctrina y erudición, a quien reconozco cedo gustoso sin atreverme a que éstas sean aún sombra a la luz de tan doctos y floridos discursos, aunque hayan sido las primeras ${ }^{12}$.

...conténtome con haber sido el primero que en nuestra España abrió la senda da esta materia, si no es traduciendo lo que se escribió en italiano, como las empresas de Giovio ${ }^{13}$.

Por azares del destino, esta obra permaneció manuscrita y no llegó a publicarse hasta 1991 y será el libro de don Diego Saavedra Fajardo, Idea de un príncipe cristiano representada en cien empresas (Munich, 1640) el que alcance la fama por ser realmente el primero publicado en español sobre empresas políticas.

Al proponernos el estudio de las fuentes del libro de empresas de los Reyes de Castilla se nos plantearon algunas cuestiones, relativas a la fecha de encargo, redacción y el lugar en que se gestó la obra, pues consideramos que contar con esta información sería muy útil para saber de qué materiales y obras disponía el autor en un lugar y un tiempo concretos para poder realizar su cometido.

Sobre la primera cuestión, solo hay algunos indicios que nos permiten aproximar un poco su datación. La obra no está fechada y no se conserva el manuscrito original; solo se han localizado dos copias posteriores: una de 1674, cuando el autor preparaba su obra para darla a la imprenta, y otra de 1695, copia del original que un secretario del Secreto de la Inquisición, encarga. El propio autor declara en el prólogo que era muy joven cuando escribió estos discursos «siendo la edad en que los escribí más para emplearla en flores poéticas que en máximas políticas», y también alude a la «tierna juventud» del Cardenal Infante: «y juntamente pudiesen estas máximas políticas dar alguna luz a la tierna juventud de Su Alteza sin que le desazonase el gusto lo dilatado de los discursos, aunque en algunas los pedía a la materia menos sucintos». Si entre don Francisco, nacido en 1595, y don Fernando de Austria, nacido en 1609, median 14 años, podríamos establecer, quizás, que fue a mediados de los años veinte del siglo XVII, cuando el cardenal Infante tendría unos dieciséis años y don Francisco no llegaba a los treinta, cuando se realizó el encargo. Si nos situamos en esa fecha podemos contar ya con la circulación de la literatura emblemática europea en España, así como con todos los textos publicados sobre la cuestión de la «razón de estado», que tanto influirán en el pensamiento político del siglo xvir. Pero lo que parece quedar claro es que, ya entonces, don Francisco era muy considerado en la corte y tenía una autoridad suficiente como para que el joven Cardenal Infante le confiase la tarea de «rescatar» y reunir las empresas utilizadas por los Reyes de Castilla.

12. Idem.

13. Op. cit., empresa 8, p. 114. 
Otra de las preguntas que se nos plantearon es dónde se gestó la obra, en qué lugar o lugares consultó don Francisco los materiales que le permitieron componer el libro. Hay constancia de que tenía ya su propia "oficina», como él mismo señala ya en el prólogo: «No el hallarme con algunos materiales para su formación me ocasionaron valerme destas empresas para que me diesen motivo a la composición desta fábrica para introd lla que tengo", etc. También Juan Antonio Fernández de la Reguera, en el breve elogio al autor que sirve de pórtico a la copia que encarga del libro de empresas, escribe:

Su estudio era una oficina general de todo género de oficios para curiosidades y primores, y tenía para su ejecución los más exquisitos y mejores instrumentos. Pintaba de porcelana en oro y cobre, hacía filigranas sutilísimas, relojes, tallaba de relieves y medio relieves en plata, acero y todo género de metales y maderas. Juntó gran copia de libros exquisitos y muchos de ellos los adicionó y marginó, y en mi poder paran algunos que manifiestan el amor y cuidado con que los trataba. Tuvo también muchas monedas, medallas y anillos que recogía de los monumentos de la más venerable antigüedad que le daban materia para descubrir sus significaciones y misterios y de ellos sacó mucho para sus obras y no poco para la de estas empresas ${ }^{14}$.

Debe tenerse presente que, además de su propio gabinete, don Francisco tendría acceso a la biblioteca del Cardenal Infante, don Fernando de Austria ${ }^{15}$, como gentilhombre de su casa ${ }^{16}$ donde tendrían asiento junto a las obras de los clásicos, obras de autores contemporáneos (Justo Lipsio, Giucciardini, Boccalini, etc.) y también las obras de los emblematistas europeos. El contexto político del momento favorecía la creación de libros de empresas políticas que ofreciesen modelos para la elaboración de un gobernante ejemplar, proponiendo generalmente, como solución básica, el tacitismo.

Con este material don Francisco compuso el libro de empresas, que estaría terminado hacia 1629.

14. Empresas de los Reyes de Castilla (2011), prólogo.

15. Hemos buscado información sobre la biblioteca de don Fernando de Austria, pero no hemos encontrado nada más que referencias a la biblioteca que tenía en Bruselas (García García, 2003), que al morir heredaría su hermano el rey, Felipe IV y que, por lo tanto, suponemos que sería incorporada a la biblioteca de la Torre Alta, que ha estudiado magistralmente F. Bouza. Existe un inventario de la biblioteca de su madre, Margarita de Austria, pero no hemos encontrado tampoco nada sobre de la de su padre, Felipe III. Es probable que don Francisco, como hombre de la corte, pudiese tener acceso también a otras importantes bibliotecas como la de Lorenzo Ramírez de Prado o la del Conde de Gondomar, en la casa del Sol en Valladolid.

16. Aunque así lo indica en la portada de su obra, no hemos podido comprobar esto en la múltiple documentación consultada acerca de la casa de don Fernando y de los escritores-criados de la casa de Austria. 


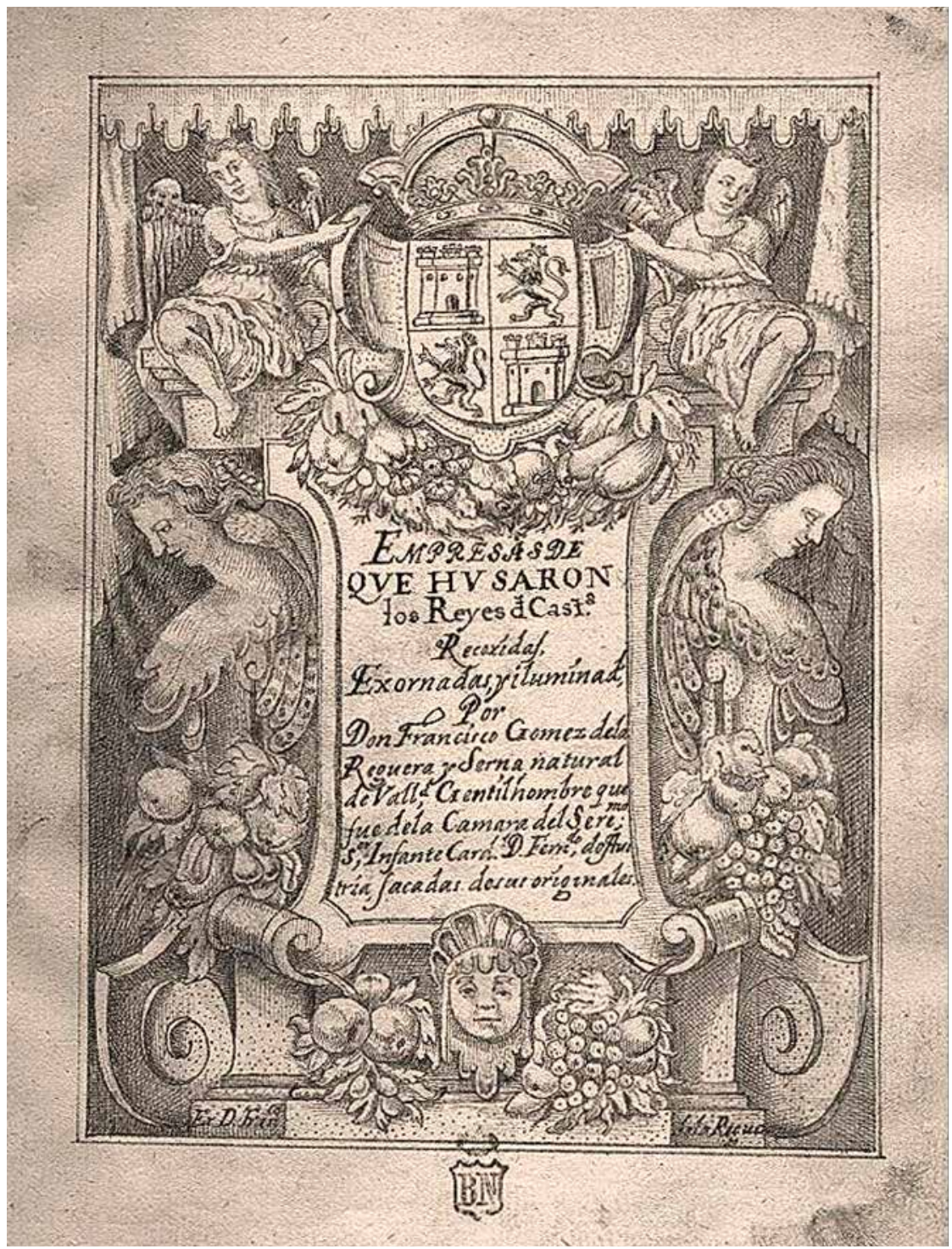

Lámina 1.

Empresas de los Reyes de Castilla. Portada. Biblioteca Nacional de Madrid.

El estudio detenido de la obra, con el análisis de las fuentes explícitas y las indagaciones sobre las implícitas, desveló detalles acerca de la formación, las lecturas y la cultura del autor, así como de la ideología que quiso transmitir. 
Para cumplir el encargo de reunir las empresas que usaron los reyes de Castilla don Francisco tuvo que usar fuentes variadas, tanto iconográficas (para los dibujos del cuerpo de las empresas) como literarias (para las glosas). Es incuestionable que los libros de empresas europeos ${ }^{17}$ tuvieron que ser una fuente primordial, aunque no lo declare. Además de estos, el autor empleó para la composición de su obra otras fuentes, que no siempre desvela.

Con unos materiales diversos, don Francisco consigue componer un libro con treinta y cuatro empresas de veintisiete reyes o consortes - de algunos reúne más de una empresa, como es el caso de Carlos V o Felipe II, por ejemplo-. La disposición de las empresas se ajusta a la estructura del emblema triplex, instaurado por Alciato: constan de una pictura que lleva un letra o mote, enmarcados en una orla con motivos arquitectónicos o marinos donde se inserta una cartela que indica el nombre del rey al que representa la empresa; le sigue un soneto y luego una glosa en prosa, al estilo de los emblematistas espańoles. Antes de la glosa el autor suele incorporar una cita de una autoridad - hay veces en que no se incluye y otras en la que introduce dos-, ofreciéndonos una galería de referencias muy variadas.

Siguiendo la costumbre humanista, don Francisco adornó el texto de la glosa con citas, mostrando así algunas de sus fuentes; pero tan interesante como el estudio de las fuentes explícitas es desvelar las otras fuentes, que el autor no descubre.

No vamos a ocuparnos aquí las fuentes de los motes, pues, como advierte Reguera, "estas empresas no han sido inventadas ni fingidas de mi ingenio. Las mismas que usaron sus dueños, pongo aquí», es decir, que suyos son los dibujos, suyo es el soneto y la glosa, pero no la invención de la empresa ni la letra. Nos centraremos, por lo tanto, en el estudio de las fuentes utilizadas para reunir y copiar las imágenes de las empresas y en las fuentes de las citas, tanto las que preceden a las glosas como las que se insertan dentro de ellas.

Para la composición de las picturae de las empresas Reguera utilizó imágenes de procedencia variada. Por un lado, es seguro que el disponía en su estudio $^{18}$ de un buen número de fuentes en que inspirarse, pues, gracias a los testimonios de diversos personajes contemporáneos sabemos que Reguera fue un buen pintor y sus dibujos e iluminaciones causaban admiración. El poeta Manuel Faria de Sousa, su amigo, dejó escrito sobre don Francisco en uno de sus comentarios a los poemas de Camões que editó: «he visto estampas de su

17. Como se ha señalado, no se habían escrito aún libros de empresas en España, pero se usaban desde hacía siglos como sabemos gracias a que se conservan las imágenes de éstas en diferentes soportes (libros, vestimentas, cimeras, armas, vajillas, edificios, etc), como representación de la identidad de sus poseedores o mecenas, o que conocemos por testimonios escritos, como relaciones de fiestas o libros de empresas (Gonzalo Fernández de Oviedo, Giovio, etc.).

18. Sería de mucha utilidad poder contar con alguna documentación sobre su biblioteca o un inventario, pero todas las búsquedas realizadas hasta el momento resultaron infructuosas. 


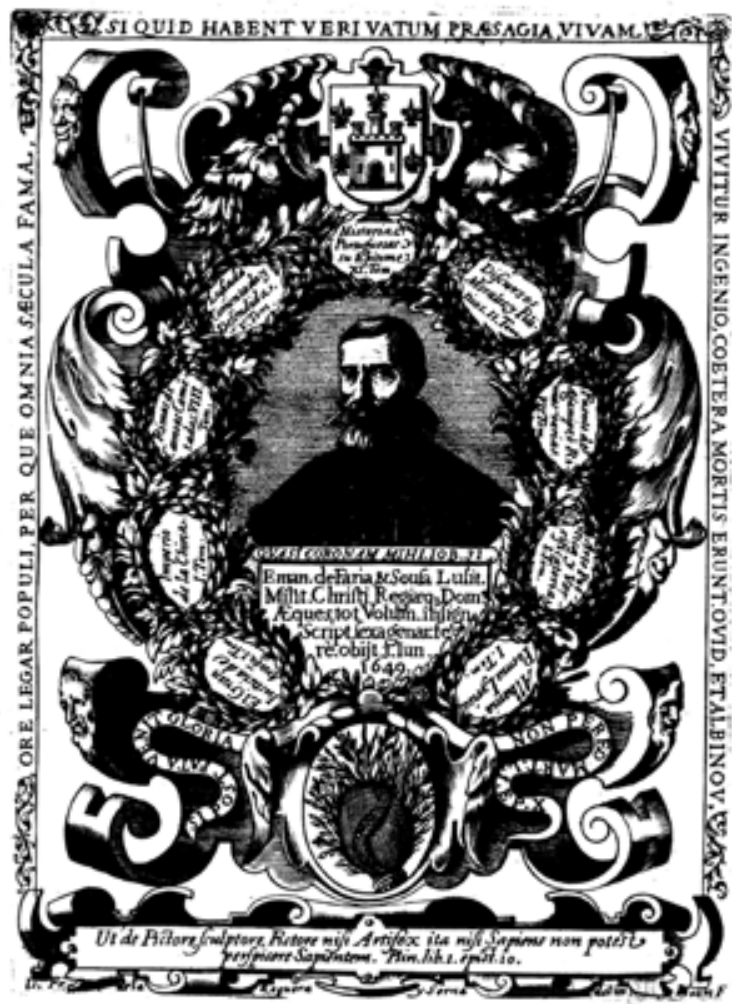

Lámina 2.

Retrato de Manuel Faria de Sousa, dibujado por Francisco de la Reguera y grabado por Noort.

pluma que me admiraron y algunas iluminaciones de gran magisterio» ${ }^{19}$. Una muestra del dominio del dibujo, además de los realizados para el libro de empresas, es el retrato del propio Faria de Sousa, que Moreno Porcel incluye en su libro (1650) y cuyo grabador será el mismo Juan Van Noort.

Por lo tanto, resultaría extraño que no dispusiese de un repertorio amplio de materiales o modelos, desde cartapacios con láminas, dibujos y estampas, libros de figuraciones alegóricas hasta monedas y medallas (y las recopilaciones e historias metálicas que proliferaron en el Renacimiento). En el libro de empresas, Reguera, únicamente hace alusión a dos obras de este tipo: la de Vin-

19. En el comentario al poema Lxxxvir de Camóes, «Ditosa pena»; vid. Luis de Camóes (1685: 299). 
cenzo Cartari, Le Imagini de I Dei de gli Antichi (Venecia, 1556), a la que hace referencia en la empresa Xxi de Isabel de Portugal, para explicar el significado de las Tres Gracias, y en la empresa Xxx, de Ana de Austria, para recordar que la serpiente es símbolo de la prudencia, pero también de la eternidad cuando se representa como ouroboros; la otra fuente que explicita es la obra de Pierio Valeriano, Hieroglyphica sive de sacris Aegyptiorum litteris commentariiy (Basilea, 1566), pues en esta obra se elogia la empresa de Alejandro Magno con el rayo, pintada por Apeles, que luego adoptó Felipe IV. Es justamente esta empresa la única en la que el autor descubre no conocer, y solicita al mismo Lope de Vega alguna información:

Debo esta empresa al felicísimo ingenio Fénix de España, Lope de Vega Carpio, que, habiéndole comunicado este trabajo para que le enmendase y diese noticias de algunas empresas de nuestros reyes a que no llegó la mía, pidiéndole en particular si el rey nuestro señor Felipe IV había usado alguna, que, aunque en una medalla del retrato de su majestad que hizo el caballero Rutilo (con la excelencia con que ejecutó otras muchas cosas) estaba en el reverso el carro del sol con la letra $I A M$ ILLUSTRAVIT OMNIA que es la mesma que usó el señor rey don Felipe II (como vimos arriba), no me pareció ponerla aquí, por no repetir una misma cosa. Y así me escribió con particulares estimaciones y alabanzas de lo escrito y ejecutado en estos cuadernos, que estimé por favores de quién también sabía honrar a los más cortos ingenios como el mío, pero que no sabía hubiese Su Majestad usado alguna, como las usaron los señores reyes sus progenitores. $Y$ así, para que pusiese entre estas me envió la presente que había hecho a Su Majestad considerando su poder y la viveza y actividad de su real espíritu ${ }^{20}$.

El autor indica en cuatro ocasiones la relación de las imágenes de las empresas reales con las monedas: así, en la empresa XvıII, dedicada a Juana de Castilla, apunta: "pudo ser tomase esta empresa de una de las monedas de Faustina que tengo de plata»; y también señala la relación de sus dibujos con las monedas en las empresas I, XVIII y XXx. Otras veces, hasta siete, revela que tomó la imagen de una medalla: "copié esta empresa de una medalla obrada con excelencia» o «Después de escrito esto, me dieron una medalla grande de nuestro emperador Carlos V armado y con la corona de laurel superiormente obrada, y a la redonda escrito IMP. CAES. CAROLUS V. AVG, y en el reverso se ve la imagen de un río con su urna, como se ve en esta...».

Es poco habitual en el libro que se indique la fuente o modelo iconográfico; no revela, por ejemplo, si ha tomado alguna idea o modelos de Giovio, cuya obra sabemos que conocía bien, y que puede que le sirviese de inspiración para la imagen análoga de la empresa de Fernando el Católico, en la que representa el nudo gordiano con el mote «tanto monta». El autor no indica tampoco su deuda con otras obras conocidas; quizás Reguera considere que esta información no es rele-

20. Gómez de la Reguera: 284. 
vante porque que el erudito de la época (al igual que el especialista en emblemas de hoy en día), reconocería en seguida una deuda con obras que en ese momento tenían difusión: colecciones numismáticas, historias metálicas, libros de empresas, etc. Así, por ejemplo, está claro que el autor utilizó la obra de G. Ruscelli, Le impresi illustri, publicada en Venecia en 1566, y sobre todo la de J. Typotius, Symbola Divina et Humana, publicada en Praga en 1601. De hecho, la pictura de quince empresas reales que incluye Reguera en su obra coincide, casi exactamente, con las hierografias $^{21}$ que representan a esos mismos reyes en la obra de Typotius.

Véase, por ejemplo, el caso de la empresa de Carlos V, que aparece en la obra de Typotius y en la de Reguera, cuyo lema hace referencia a la veneración al honor de los antepasados. Para la representación de esta empresa, ambos autores pudieron insipirarse en medallas; en realidad se acuńaron dos medallas casi iguales, con el mismo lema, IN SPEM PRISCI HONORIS que tenían en el anverso la imagen de Carlos $\mathrm{V}$ de perfil y en el reverso un anciano desnudo y con barba, sentado en unas rocas, que portaba entre sus manos un cántaro que arrojaba agua, representando un caudaloso río; debajo una pequeña cartela con el nombre del río, y aquí radicaba la diferencia. La medalla con el nombre DANUBIUS estampado parece que se acuñó hacia 1527 y su creador fue el artista Leone Leoni, considerado el mejor medallista de la época, que ya había realizado varias medallas para el emperador; la segunda medalla, con la inscripción al pie del anciano TIBERIS se acunó en 1530 para la coronación del emperador en Bolonia, aprovechando todos los materiales anteriores (que se reproduce en la obra de Typotius); seguramente podría interpretarse esta reutilización y reorientación de la empresa utilizando la alegoría del Tiber o del rey de Alba Longa, Silvio Tiberino, con el objetivo de reconciliar a la figura del emperador con la ciudad de Roma tras el saco de 1527 (la referencia iconográfica a la ciudad eterna en términos alegóricos se hizo también en dos medallas de los Papas León X y Paulo III), aunque la referencia alude a la divinidad Tiber/Tiberino más que a la ciudad y a sus instituciones.

21. Utilizo el mismo término que emplean Gómez de la Reguera y Typotius para referirse a las empresas de los reyes. Posteriormente, utiliza el mismo término Raymond de Petity (1770). 


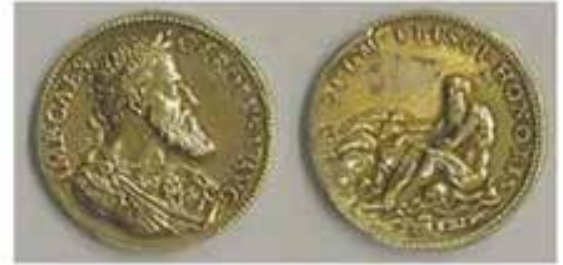

Medata de Carios V, Leane Lech

Museo Lazaro Galdano, Madni

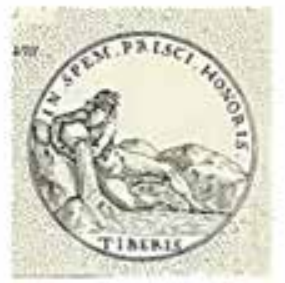

Typotiss, 1, Symbote divine et humans, Proge, 1601.

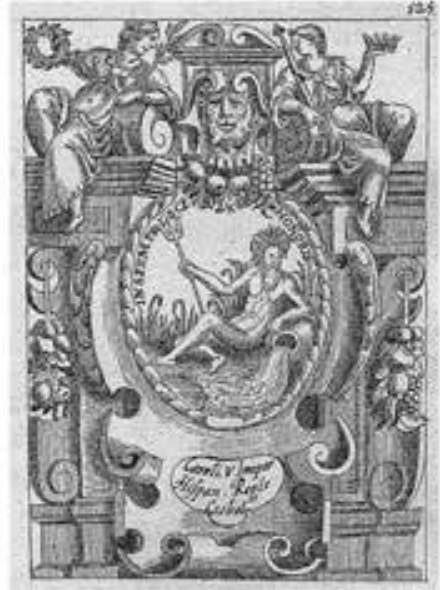

Emoresa de Carlos V, Francisco de ta Reguera, Empresas delos Reves de Castala

\section{Lámina 3.}

Empresa de Carlos V y sus posibles fuentes.

Otro ejemplo claro de la utilización de imágenes con contenido simbólico reconocible es la empresa de María Tudor, segunda esposa de Felipe II, Caecis timidis visus quies, que recogen las obras de Ruscelli, Typotius o Luck. En la glosa a esta empresa el propio Reguera desvela de donde ha tomado la imagen, incluyendo incluso un dibujo de una medalla en el libro:

cuando los romanos hacían una paz general cerraban el templo de Jano, como se ve en algunas medallas de aquel tiempo, y en una que tengo entre no poca cantidad que he juntado, que es de Nerón y bien obrada se ve la forma del templo de Jano con esta inscripción: PACE P.R. TERRA MARI Q. PERACTA IANUM CLUSIT S. C., que la pongo aquí en honor de la antigüedad. 


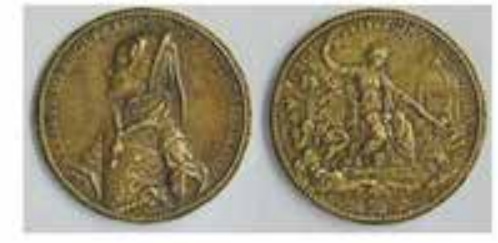

Medalla de Maria de Inglaterra

Museo Lázaro Galdiano (Madrid)

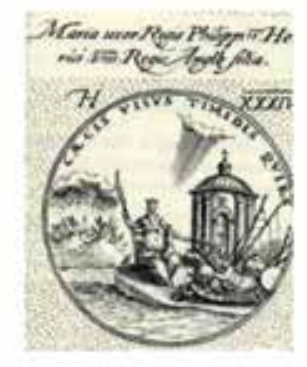

Typotius, 1., Symbola divina et humana, Praga, 1601.

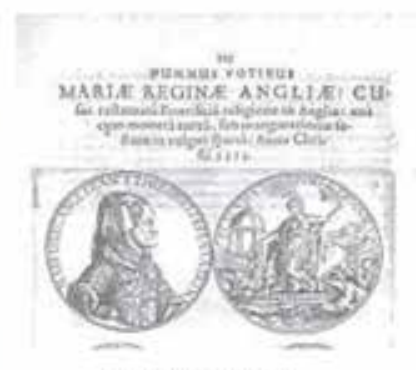

Lück, 3, 3., Syïlage numismatum, 1620.

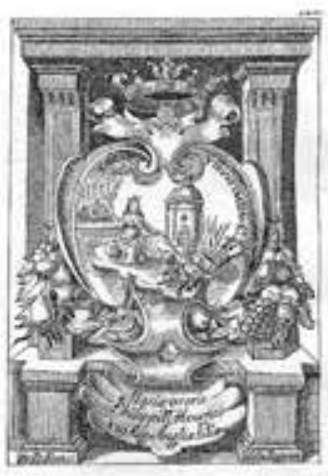

Empresas., empresa Xxvm

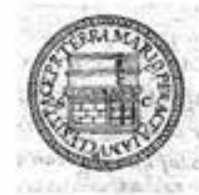

Reguera, F., Empresas., empresa xxvitt, medalla de Nerón propiedad del autor.

\section{Lámina 4.}

Empresa de María Tudor y sus fuentes.

En el caso de la empresa de Carlos II, añadida hacia 1673, cuando se preparaba el texto para la imprenta, la fuente era bien conocida para los contemporáneos pues las monedas circulaban con esa misma imagen, como puede constatarse en diferentes monedas acuñadas entre 1665 y 1700 (de 1 real, 2, 4 y 8 reales,) donde se reproduce la imagen, con la misma letra, pero en orden inverso: Protectione virtute 22

22. Una explicación de la utilización de la simbología político-religiosa puede encontrarse en Francisco de Olmos (2006): «por una parte está la puramente política, esta moneda es de menor valor que la anterior y para que el pueblo la aceptara se buscaba hacerla atractiva tipológicamente, incluso haciendo alusión a algo sobrenatural, en este caso el monograma de la Virgen María, en un momento de gran exaltación mariana, intentando poner, como dice la leyenda, bajo la protección de la Virgen la moneda y el éxito de la reforma [... . Felipe III formó la Real Junta de la Inmaculada, para defender y promover el dogma, que sus sucesores mantuvieron como cuestión de Estado, y Carlos II no fue la excepción, promoviendo fiestas y consiguiendo de Roma la aceptación de celebrar este culto en España, por lo cual era otra manera de promover esta política a través de unas acuńaciones nuevas y extraordinarias en el numerario castellano, poco dado a colocar tipos religiosos en sus piezas". 


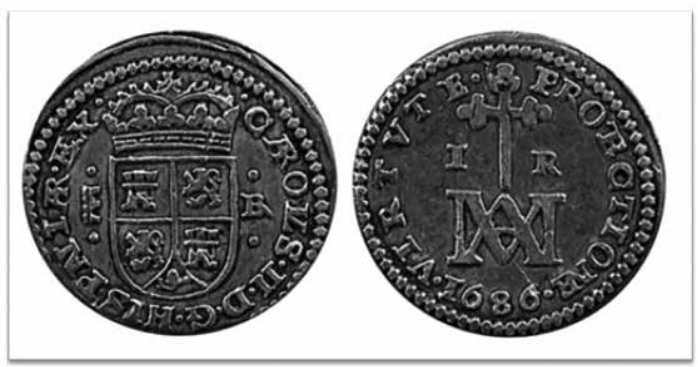

Moneda de Carlos II

Museo de Bellas Artes de A Coruña

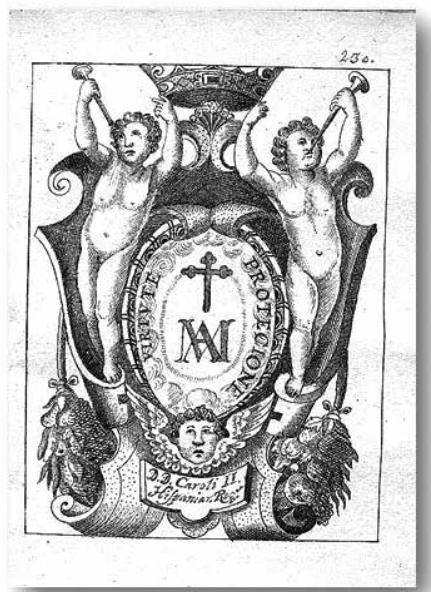

Gómez de la Reguera, F., Empresas..., empresa XXXV

\section{Lámina 5.}

Empresa de Carlos II.

Además de las fuentes ya señaladas (monedas, medallas y libros de empresas europeos), don Francisco podría tomar las imágenes para el cuerpo de las empresas de las que lucieron sus poseedores en la fiesta pública y que pudo conocer a través de retratos, dibujos, cuadros e incluso en las descripciones que se insertaban en las relaciones festivas.

Sobre las fuentes que utiliza para los textos, hay que diferenciar las utilizadas en las citas que don Francisco suele incluir antes de la glosa, y las fuentes de las glosas. Llevan cita antes de la glosa veintiuna empresas (un 60\%), de treinta y cinco que contiene la versión que se prepara para la imprenta en 1674. La función de estas citas es exhibir la erudición del autor al tiempo que se evidencia el interés del tema de la empresa, ya tratado por autores reconocidos. Generalmente estas citas suelen ocupar una o dos líneas, duplicando o triplicando al mote en longitud. Sirva como ejemplo la cita inserta antes de la glosa explicativa de la empresa de Alfonso XI de Castilla, que representa un armińo con el mote Malo mori quam foedari; la cita, tomada del Panegírico de Trajano, de Plinio el Joven, es la siguiente: «Vita principis censura est eaque perpetua», que incide en el tema de la pureza o virtud sin mancha que ha de adornar la vida de un príncipe. Por lo que respecta a las autoridades citadas, hay que señalar que utiliza una gran variedad: Séneca, Tácito, Aristóteles, Plinio el Joven, Plutarco, Casiodoro, San Basilio Magno, etc., predominando los dos primeros (con cinco citas de cada autor). 
Gómez de la Reguera utiliza las glosas para explicar las empresas reales insistiendo en el concepto político y también moral. Siguiendo el procedimiento habitual en la época, salpica la glosa de citas en latín (que el copista del manuscrito resalta con letra redonda, para diferenciarlo del texto en castellano, en letra cursiva, probablemente imitando el manuscrito original regueriano) y suele anotar en apostillas marginales la procedencia y/o algún comentario. Solo en la empresa 18, la atribuida a Juana la Loca, la glosa no se adorna con citas.

Don Francisco muestra en las glosas una gran capacidad para adornar e ilustrar su argumentación utilizando, y ensamblando a veces, una cita de autores clásicos o bíblica, una anécdota de la historia clásica, un dicho o un ejemplo de la historia contemporánea. Esta labor de engarce se corona con una indicación rigurosa de las fuentes de las glosas, aunque en alguna ocasión la cita no es exacta. De doscientas cincuenta citas, en cincuenta (un 20\%) no se indica de dónde provienen (aunque normalmente se han averiguado: Tácito, Lipsio, Cicerón, Virgilio, Séneca, Plinio, Juvenal, etc.).

En el libro Empresas de los Reyes de Castilla se citan 77 autores y, se incorporan referencias de algunos libros de la Biblia (sobre todo del Antiguo Testamento).

Entre los autores paganos más citados en las glosas están ${ }^{23}$ : Tácito (con 63 citas, un 25,2\% $)^{24}$ sobre todo los Annales y la Historiae; Cicerón (con 24 citas de once obras, 9,6\%); Séneca (23 citas de hasta trece obras diferentes; un 9,2\%); Aristóteles (12 citas, un 4,8\%); Salustio (9, 3,6\%); Tito Livio y Plinio el Joven (8 citas, un 3,2\%), Quinto Curcio (6 citas); Justo Lipsio (5 citas), Virgilio y Platón (4 citas). Otras autoridades de referencia en la obra, aunque con menos presencia, son (3 o menos citas): Ovidio, Camóes, Jenofonte, Casiodoro, Juvenal, Pontano, Alfonso X, Petrarca, Reginaldo Polo, etc.

A propósito de Justo Lipsio, uno de los autores más venerados en nuestro país, hay que señalar que don Francisco solo indica en dos ocasiones que sus citas proceden de este autor: la primera vez es en la empresa 1, de Ramiro II en la que utiliza una cita de la obra de Lipsio, De cruce; la segunda es en la empresa 13, de Pedro III de Aragón, en la que alude a la obra De re militare. Hemos podido identificar, por lo menos, tres citas (empresas 16 y 17, de Fernando el Católico, y empresa 20, de Carlos I) de su obra más polémica, Politicorum sive Civilis Doctrinae, libri sex. Qui ad Principatum maxime spectam, publicada en Leiden en 1589, además de otras alusiones. La razón de que las referencias a Lipsio sean veladas, y, sobre todo a esta obra, se debe a que el Vaticano la incluyó en el Index

23. Ha de tenerse en cuenta que el recuento de citas se ha realizado sobre el número total, y no únicamente sobre las que identifica Gómez de la Reguera.

24. «La obra de Lipsio está construida, según propia confesión, sobre conceptos tacitianos, y si bien no constituye un conjunto de doctrinas compactas y bien delimitadas, sus opiniones no sistematizadas poseen un núcleo consistente, capaz de incrementar con fuerza la penetración de Tácito en España, sobre todo porque Lipsio inicia la incorporación de Tácito al clima ideológico de la Contrarreforma», vid. Tierno Galván (1991). 
Librorum Prohibitorum en $1590^{25}$. Está claro que Gómez de la Reguera conoció bien la obra ${ }^{26}$ (pudo haberla leído en latín, pues era un excelente latinista, o en la traducción de 1604 de Bernardino de Mendoza, dedicada «a la nobleza espańola para que no pase sin tan provechosa lectura») y es evidente que Lipsio está presente en las Empresas, aunque no se cite explícitamente. Valga como muestra lo que ocurre en la glosa de una de las empresas de Carlos I, la que lleva por mote "PLUS ULTRA»: el autor insiste en la importancia de la conservación de los estados y la paz de los reinos y para ilustrar esta idea incluye en el texto una cita de Séneca (aunque sin indicar su autoría), "quod alter arma habet, quibus in monimentum pacis utitur. Alter ut magno temore, magna odia compescat», cita que, casualmente, es utilizada también por Lipsio en el libro IV de su Política; en esta misma empresa, más adelante, se inserta una cita de Quinto Curcio, que también está en Lipsio, y luego en Saavedra Fajardo.

Con respecto a los libros de empresas, obras de figuraciones alegóricas o mitológicas, en la obra, además de Giovio, solo aparecen citadas otras dos: las de V. Cartari y Pierio Valeriano.

Aunque las citas utilizadas en las glosas proceden, sobre todo, de fuentes profanas, no pueden obviarse las referencias a la Biblia (28 citas, un 11,2\% del total), sobre todo del Antiguo Testamento (7,6\%) y menos del Nuevo Testamento $(3,6 \%)$. Los libros sagrados más citados son: Proverbios, Salmos, Eclesiastés (4), Mateo, Lucas (3), Reyes (2), Génesis, Esther, Jeremías (1). Entre las obras de Padres y Doctores de la Iglesia cita sobre todo a San Agustín (6), Santo Tomás (3), San Gregorio, San Isidoro (1), San Basilio Magno, S. Juan Crisóstomo, etc.

Como ya se ha señalado, Gómez de la Reguera cita con bastante precisión, pero esto no significa que acuda siempre a las fuentes originales, pues hay huellas de que, siguiendo el método humanístico, utilizó un codex excerptorius. Así, en la empresa XIII aclara en una de las apostillas marginales: «Cristofo Forstuerio, Tac. Ann.2, fol. mihi 3002", que parece indicar que toma la cita de una anotación suya en su cartapacio personal. La utilización de los excerpta podría justificar también el uso de un número elevado de citas de diferentes obras de Séneca y Cicerón, así como el empleo de un buen número de referencias de otros autores que se utilizan una sola vez (Calímaco, Marcial, Jenofonte, etc.).

25. Como ya ha demostrado S. López Poza (2008) que ocurre en las Empresas Politicas de Saavedra Fajardo.

26. Aunque, como se ha dicho, la obra se incluyó en el Índice de Libros Prohibidos muy pronto, hay constancia de que siguió circulando y de que en España hubo ejemplares. Así sabemos, gracias al estudio de los inventarios de bibliotecas del Siglo de Oro, que la biblioteca de Lastanosa albergaba 9 ejemplares, entre ellos la Política, en traducción de Bernardino de Mendoza, editada en 1640; 10 ejemplares poseía el Conde de Gondomar en su biblioteca, 15 había en la de Ramírez de Prado, y por lo menos uno en la biblioteca de Medinaceli y en la del Conde duque de Olivares (véase $<$ http://www.bidiso.es/IBSO>). Es más que probable que la biblioteca del Cardenal Infante, que pudo consultar Gómez de la Reguera, contase también con obras de Lipsio. 
Además del codex excerptorius, los libros de dicta e facta se utilizaron en la elaboración de la obra: así, el famoso Factorum ac dictorum memorabilium de Valerio Máximo, aparece citado en la empresa IV. A buen seguro Gómez de la Reguera también se serviría alguna poliantea o libro de lugares comunes como materiales auxiliares para la redacción de su obra, como puede deducirse por la presencia de las conocidas anécdotas de ciertos personajes históricos como Alejandro Magno, Scévola, Sejano, etc.

Resulta, cuando menos, curioso, comprobar que las Empresas políticas de Saavedra Fajardo coinciden en doce citas, un 4,8\%, con las de Reguera. Los autores y obras que coinciden son: Tácito (Anales e Historia), Silio Itálico, Cicerón, Salustio, Virgilio (Eneida), Casiodoro, Jenofonte y, en la Biblia, una cita del Eclesiástico. La cuestión que se nos plantea es si esta coincidencia es solo un reflejo de la manera de trabajar de los hombres del siglo Xvir (lecturas comunes, utilización de codex excerptorius, etc.), si se trata de una coincidencia ideólogica, o de si Saavedra conocía (y pudo servirse de) la obra de don Francisco, pues esta circuló un tiempo por la corte.

Con estos materiales (medallas, monedas, libros de emblemas europeos, obras de autores clásicos y contemporáneos, etc.) y otros, Gómez de la Reguera consigue hacer el encargo: un libro que reúne las empresas de reyes de Castilla. La obra ofrece treinta y cinco empresas desde la Edad Media hasta el fin de la dinastía de los Austrias, dispuestas sin seguir un estricto orden cronológico hasta el siglo Xv. No sabemos si la escasez de fuentes y datos sobre las divisas de los reyes que se omiten fue la causa de la selección (y el desorden de las de reyes medievales), pero este no parece ser el motivo de la ausencia de algunas como la de la reina Isabel la Católica, muy conocida, o la de su padre, Juan II. La dispositio de las empresas hacen pensar en una cuidada preparación, quizás para ofrecer un libro único al cardenal Infante, o quizás para dar a la imprenta; sin embargo, las empresas no sigue un orden cronológico hasta el siglo xvI y, como se ha señalado, faltan algunas de las más conocidas, lo que nos lleva a barajar la posibilidad de que la obra esté inacabada, o, posiblemente, estemos solo ante un borrador de un libro de empresas completo y más amplio.

Son muchas las incógnitas (cuándo fue encargada la obra, dónde se gestó, por qué no se incluyen ciertas empresas, etc.), pero, lo que queda claro es que don Francisco Gómez de la Reguera poseía una sólida formación y cultura de la que hace gala en esta obra y tenía a su alcance un rico caudal de materiales diversos.

En definitiva, el estudio de las fuentes de esta obra muestran datos muy interesantes para el conocimiento de la erudición del autor y la construcción de su libro de empresas y es de enorme interés para desvelar la ideología que subyace en esta obra, concebida no solo como libro de empresas sino también como «espejo del príncipe», guía de uso y actuación política del gobernante.

El autor, siguiendo la estela de Giovio, reúne las empresas de reyes castellanos, y confecciona un libro de empresas políticas. Las fuentes explícitas que el 
autor incluye desvelan una formación íntegra y completa, al tiempo que muestran el deseo de transmitir una ideología política: el tacictismo. Es de destacar la gran influencia de los clásicos latinos, sobre todo Tácito, Cicerón y Séneca, y también el uso muy medido de las obras religiosas.

Tras la investigación de las fuentes implícitas hemos podido descubrir el gran influjo de la obra de los humanistas flamencos Justo Lipsio y Typotius ${ }^{27}$, que, el autor evitó citar expresamente, quizás para evitar reticencias si la obra llegaba a publicarse.

Aunque el nombre de Francisco de la Reguera apenas es conocido por los estudiosos del Siglo de Oro en la actualidad, fue un personaje célebre y muy apreciado en la Corte y en su Valladolid natal, según se desprende de su obra y de la documentación que se conserva. El estudio de las fuentes que utilizó para la composición de su obra Empresas de los Reyes de Castilla muestran a un perfecto humanista, un erudito del siglo XvI, que domina a la vez el arte de hacer un soneto, la maestría de la glosa (en la que utiliza magistralmente los exempla para ilustrar su argumentación) y la técnica del dibujo. El gusto por la Historia por su utilidad para obtener enseñanzas útiles para su tiempo, la utilización de la obra de Tácito, Séneca y Cicerón como fuente prioritaria para lecciones políticas, o la necesidad de unir el saber y la ideología política con una ética civil son características que se desprenden de la lectura de su obra y del análisis de sus fuentes y coinciden con la de contemporáneos suyos como Saavedra Fajardo.

27. Aunque parece que J. Typotius fue católico, quizás el haber nacido en Brujas y haber vivido en la corte de Rodolfo II, lo convertían en sospechoso. De hecho, su nombre aparece en el Novo index liber prohibitorum de 1620. No era conveniente, por lo tanto, citarlo. 


\section{Bibliografía}

Antón Martínez, Beatriz, El Tacitismo en el Siglo XVII en España: El Proceso de Receptio, Valladolid, Universidad, 1991.

Camốes, Luis de, Rimas varias... comentadas por Manuel de Faría y Sousa, Lisboa, con privilegio real, en la Imprenta de Theotonio Damaso de Mello, impresor de la Casa Real, con todas las licencias necesarias, 1685.

Choul, Guillermo de, Los discursos de la religión, castramentaçión, assiento del campo, baños y exerçiçios de los Antiguos Romanos y Griegos... traducido del castellano de la lengua francesa por el maestro Balthasar Perez del Castillo, canónigo y natural de la ciudad de Burgos, Lyon, Guillelmo Rovillio, 1579.

Francisco De Olmos, José $\mathrm{M}^{\mathrm{a}}$, «Novedades tipológicas en la moneda de la monarquía hispánica del siglo XVII", en $V$ Jornadas sobre documentación en Castilla e Indias en el siglo XVII, Madrid, 2006, 105-164, <http://www.ucm.es/centros/cont/descargas/documento11375.pdf>

García García, Bernardo, «El legado de arte y objetos suntuarios de las testamentarías de Isabel Clara Eugenia y el Cardenal Infante (1634-1645)», en Arte y diplomacia de la Monarquía Hispánica en el siglo XVII por José Luis Colomer (dir.), ediciones en colaboración con CEEH y Casa Velázquez, 2003, 135-159.

García López, Jorge, «Observaciones sobre la tradición clásica en las Empresas políticas", Studia Aurea Monográfica, 1. Literatura, sociedad y política en el Siglo de Oro, (2010), 335-352.

García Vega, Blanca, "Las Empresas de los reyes de Castilla y de León, de Francisco de la Reguera», en Actas del I Simposio Internacional de Emblemática, Teruel, 1 y 2 de octubre de 1991, Teruel, Instituto de Estudios Turolenses, 1994, 93-169.

Grovio, Paolo, Diálogo de las empresas militares y amorosas, compuesto en lengua italiana por el ilustre y reverendísimo Señor Paulo Iovio Obispo de Nucera. En el qual se trata de las devisas, armas, motes o blasones de linages. Con un razonamiento a ese propósito del magnifico Señor Ludovico Domeniqui. Todo nuevamente traducido en romance castellano por Alonso de Ulloa. En León de Francia, en casa de Guillelmo Roville, 1561.

Gómez Martínez, J. L., «Los supuestos modelos de las 'Empresas' de Saavedra Fajardo y su carácter ensayístico», NRFH, XXVIII (1979), 373-384.

Gómez De La Reguera, Francisco, Empresas de los reyes de Castilla, edición de Nieves Pena Sueiro, A Coruña, SIELAE y Sociedad de Cultura Valle Inclán, 2011.

Grigoriadu, Theodora, «Francisco de la Reguera: un traductor más y único continuador de Luciano de Samósata en el Siglo de Oro» $C F C(G)$ : Estudios griegos e indoeuropeos, (2006) 16, 181-193.

Lamarca Ruiz De Eguílaz, Rafael, «De la moneda al emblema. Los repertorios y colecciones numismáticas como fuentes de inspiración para la Literatura Emblemática», en Sagrario López Poza (ed.), Literatura Emblemática His- 
pánica, Actas del I Simposio Internacional (A Coruña, 14-17 de septiembre, 1994), A Coruña, Universidade da Coruña, 199, 533-556.

López PozA, Sagrario, «Linajes de aguda invención figurada: las empresas», en Paisajes emblemáticos: la construcción de la imagen simbólica en Europa y América, César Chaparro, José Julio García, José Roso y Jesús Ureña (eds.), Cáceres, Editora Regional de Extremadura, colección Estudio, 34, 2008, 17-64.

—, Sagrario, "La Política de Lipsio y las Empresas políticas de Saavedra Fajardo», Res Pública. Revista de filosofía, política. Saavedra Fajardo y su época, núm. 19, año 11 (2008), 209-234.

—, Sagrario, «Signos de identidad en el Siglo de Oro» en VIII Congreso AISO "Compostella áurea", 7-11 de julio de 2008, Santiago de Compostela, 2011.

Moreno Porcel, Francisco, Retrato de Manuel de Faria y Sousa. Contiene una relación de su vida, un catálogo de sus escritos, Madrid, 1650.

Mout, Nicolette, «A Useful Servant of Prices: The Netherlandish Humanist Jacobus Typotius at the Prague Imperial Court Around 1600» Acta Comeniana 13 (1999), 27-49.

Pena Sueiro, Nieves, «Las Empresas de los Reyes de Castilla de Francisco Gómez de la Reguera a la luz de un nuevo testimonio", Boletin de la Real Academia Española (2009) Tomo 89, no 300, 343-363.

—, Nieves, «Las empresas de las reinas de Castilla (1504-1611)», en Rafael Zafra y José Javier Azanza, Emblemática trascendente. Hermenéutica de la imagen, iconología del texto, Pamplona, SEE- Universidad de Navarra, 2011, 639-649.

Raymond De Petity, Jean, Le Manuel des artistes et des amateurs, Paris, 1770.

Rivadeneyra, P. (S.I.), Tratado de la Religión y virtudes que debe tener el Principe Cristiano para gobernar y conservar sus Estados, contra los que Nicolás Maquiavelo y los políticos deste tiempo enseñan. En Madrid, en la emprenta de P. Madrigal a costa de Juan de Montoya, 1595.

Ruscelli, G., Le imprese illustri, in Venetia, apresso Francesco Rampazetto, 1566.

SaAvedra Fajardo, Diego, Empresas políticas, ed. de Sagrario López Poza, Madrid, Cátedra (Letras Hispánicas, 455), 1999.

Simón Díaz, J., «Los escritores-criados en la época de los Austrias», Revista de la Universidad Complutense, Madrid, 1981-1982, 169-177.

Tierno Galván, Enrique, «El tacitismo en las doctrinas políticas del siglo de oro español» recogido en Escritos (1950-1960), Madrid, Tecnos, 1991, 11-93.

Urrea, Jerónimo, Diálogo de la verdadera honra militar, Venetia, en casa de Giovanni Griffio, 1566.

Typotius, Jacob, Symbola Divina et Humana Pontificum Imperatorum Regum, Pragae, ex Musaeo Octavi de Strada civis Romani, 1601, tomo I; 1602 tomo II; 1603 tomo III. 
